\title{
Infant Auditory Temporal Acuity: Gap Detection
}

\author{
Lynne A. Werner and G. Cameron Marean \\ University of Washington
}

\section{Christopher F. Halpin}

University of Virginia

\section{Nancy Benson Spetner and Jay M. Gillenwater}

\author{
University of Washington
}

\begin{abstract}
Werner, Lynne A.; Marean, G. Cameron; Halpin, Christopher F; Spetner, Nancy Benson; and Gillenwater, Jay M. Infant Auditory Temporal Acuity: Gap Detection. ChIld DevelopMENT, 1992, 63, 260-272. The development of auditory temporal acuity during infancy was examined in 3-, 6-, and 12-month-old infants and in adults using the gap detection paradigm. Listeners detected a series of gaps, or silent intervals, of variable duration in a broadband noise. In order to vary the acoustic frequencies available to the listener, a high-pass noise was used to mask frequencies above specified cutoffs. High-pass maskers with cutoffs of $500,2,000$, and $8,000 \mathrm{~Hz}$ were used. The minimum detectable gap was determined using the Observer-based Psychoacoustic Procedure. The thresholds of 3- and 6-month-olds were considerably poorer than those of the adults, although the effect of masker condition was about the same for these 3 groups. The thresholds of 12-month-olds were significantly worse than the adults when the stimulus was unmasked or when the masker cutoff frequency was 2,000 or $8,000 \mathrm{~Hz}$. When the masker cutoff frequency was $500 \mathrm{~Hz}, 12$-month-olds fell into 2 groups: some had gap thresholds that were about the same as 3- and 6-month-olds, while some had gap thresholds that approached those of adults. In a second experiment, a larger group of 12-month-olds were tested with a $500-\mathrm{Hz}$ masker cutoff. Average performance of 12-month-olds was about the same as that of 3- and 6-month-olds in Experiment 1. Some infants attained thresholds close to those of adults. Thus, gap detection thresholds are quite poor in infants, although the similarity of the effect of frequency on performance in infants and adults suggests that the mechanisms governing temporal resolution in infants operate qualitiatively like those in adults.
\end{abstract}

Temporal cues have frequently been shown to be critical to both human and nonhuman communication (e.g., Gottlieb, 1985; Pisoni, 1977). Moreover, a relation between temporal acuity and the ability to understand speech has been demonstrated among human listeners (e.g., Dreschler \& Plomp, 1980). The few studies examining the development of temporal acuity suggest that immaturity of this capacity may even persist into childhood. Davis and McCroskey (1980) determined the duration of a silent interval between two tone bursts required for children to report hearing two sounds rather than one sound. The threshold duration de- creased progressively between 3 and 11 years. A similar age effect was observed for all tone frequencies and intensities. Irwin, Ball, Kay, Stillman, and Rosser (1985) measured gap detection threshold, or the minimally detectable silent interval in a continuous sound, for children and adults. They found that 6-year-olds had higher gap detection thresholds than older children or adults. This effect was more pronounced at lower intensities and when a low-frequency noise band was the stimulus. In contrast, Wightman, Allen, Dolan, Kistler, and Jamieson (1989) found that 6-year-olds were adultlike in gap detection at both 400 and $2,000 \mathrm{~Hz}$.

Preliminary report of these data was made at the Midwinter Meeting of the Association for Research in Otolaryngology, Clearwater Beach, FL, February 1986. Requests for reprints should be addressed to L. A. Werner, CDMRC, WJ-10, Box 47, University of Washington, Seattle, WA 98195. This research was supported by NIH grant DC00396 to L. A. Werner. C. Halpin's current address is: Massachusetts Eye and Ear Infirmary, Audiology Dept., 243 Charles St., Boston, MA 02114. N. Spetner's current address is: AT\&T Bell Laboratories, Rm. 2D-602A, Crawfords Corner Road, Holmdel, NJ 07733-1988. 


\section{Werner et al. 261}

These investigators reported that 3-year-olds were poorer than adults in gap detection at both frequencies; however, they were also able to simulate the thresholds of these children by assuming that the children were inattentive on a high proportion of trials. Thus, whether temporal resolution is mature among preschool and school age children is not clear.

Morrongiello and Trehub (1987) have published the only developmental study of temporal resolution that included infant subjects. They found that adults responded to a smaller change in the duration of a repeated noise burst than did 5.5-year-old children, who in turn responded to smaller changes in duration than did 6-month-old infants. While these age differences may result from differences in temporal acuity, one cannot dismiss the possibility that they result from immaturity of performance factors (e.g., attention) not directly related to the auditory system.

The purpose of the current study was to assess temporal acuity among human infants. A gap detection technique, similar to that employed in earlier studies (e.g., Fitzgibbons \& Wightman, 1982; Irwin et al., 1985; Irwin, Hinchcliffe, \& Kemp, 1981) was used. Because several studies of infants in our own as well as other laboratories suggest that the rate of auditory development depends on sound frequency (e.g., Olsho, 1984; Olsho, Koch, Carter, Halpin, \& Spetner, 1988; Olsho, Koch, \& Halpin, 1987; Schneider, Trehub, \& Bull, 1980; Sinnott, Pisoni, \& Aslin, 1983; Trehub, Schneider, \& Endman, 1980), the effect of frequency on the development of temporal processing was of particular interest.

The manipulation of stimulus frequency in the gap detection paradigm is not a trivial problem. A pure tone is the most frequency specific sound that might be used. The most straightforward way to introduce a gap of known duration into a sound is to abruptly switch the sound off and on again. However, this abrupt switching creates spectral "splatter" (i.e., the spectrum of the stimulus will contain energy at a range of frequencies around that of the original pure tone). While use of a narrow band of noise rather than a pure tone alleviates this problem to some extent, it does not eliminate it. Furthermore, the waveform of a noise band has pronounced variations in amplitude that may be confused with a gap. The frequency and extent of such amplitude variations are related to the bandwidth of the stimulus and, hence, usually to the stimulus frequency. Thus, one explanation for the pronounced age difference in gap detection of low frequency noise bands observed by Irwin et al. (1985) is that younger children were more easily confused by these "dips" in the waveform than were older listeners.

In the current study, an interrupted broadband noise was the stimulus in all conditions. The duration of the interruption, or gap, was varied to determine gap detection threshold. Frequency was manipulated by varying the low-frequency cutoff of a continuous high-pass masking noise presented simultaneously with the interrupted stimulus. A broadband noise contains energy over the entire range of audible frequencies. When gaps are introduced in a broadband noise, the listener can use information in any frequency region to detect the gaps. A highpass noise contains only frequencies above its low-frequency cutoff. With such a noise presented at a sufficiently high intensity, the portion of the broadband stimulus above the cutoff of the masker would be inaudible. Only those frequencies below the cutoff would be available for detecting gaps in the broadband stimulus. While this stimulus configuration avoids the problems inherent in the use of noise bands, it confounds frequency with bandwidth. In other words, as the cutoff frequency of the masker is increased, the bandwidth of the stimulus that can be used to detect gaps also increases. Shailer and Moore $(1983,1985)$ have shown, however, that in the range of bandwidths used here, the effects of bandwidth are minimal compared to the effects of stimulus frequency for adult listeners.

\section{Experiment 1}

\section{Method}

Subjects.-The infant subjects were 17 3-month-olds, 19 6-month-olds, and 14 12month-olds. These subjects provided 86 acceptable data sets. An additional 84 sessions were attempted but excluded for the following reasons: training criterion not met $(21)$; insufficient data (7); false alarm rate too high (51); psychometric function slope not greater than zero (5). About half of the excluded sessions were from the infants who eventually contributed thresholds to the final data set. The rest were from seven 3-month-olds, nine 6-month-olds, and eight 12-month-olds who never provided usable data, typically because they did not return for testing after the first or second session. All subjects met the following criteria for inclusion: (1) full- 
term gestation and normal pre-, peri-, and postnatal developmental course; (2) no history of hearing dysfunction and no family history of congenital hearing loss; (3) no occurrence of middle ear infections within 2 weeks of testing and no more than 2 prior occurrences of middle ear problems. All infants completed testing within 2 weeks of the age given.

Eleven 20-30-year-olds were the adult subjects. All were undergraduate or graduate students. All reported normal hearing and no history of hearing dysfunction. None of the adult subjects had prior experience listening in psychophysical or other auditory experiments. Adults were tested in two sessions; one of the adult subjects completed only one session.

Data with respect to subject race, gender, and socioeconomic status were not systematically collected.

Stimuli and apparatus.-Two independent noise generators (Coulbourn S81-02) were used to produce the stimulus and masker. The stimulus noise was presented at a spectrum level ${ }^{1}$ of $30 \mathrm{~dB}$ SPL. Gaps were created in the noise by gating the stimulus off and on with a rise/fall time less than 1 ms. Gap duration could be varied between 0 and $125 \mathrm{~ms}$ in $1-\mathrm{ms}$ steps. A series of 10 gaps, each gap followed by $500 \mathrm{~ms}$ of noise, constituted a "signal" trial. Using this rather long "intergap interval" ensured that subjects could not use changes in the overall loudness of the stimulus to detect gaps. Although this procedure meant that trial duration changed as gap duration changed, once gap duration reached near threshold values, the resulting change in duration would be negligible.

The masker noise was high-pass filtered with cutoffs of $500,2,000$, or $8,000 \mathrm{~Hz}$ (i.e., frequencies above the cutoff were passed by the filter, while frequencies below the cutoff were not). These frequencies would be expected to result in different levels of performance in adults, and they represent frequencies where infants perform differentially relative to adults in other tasks (e.g., Olsho, 1984; Olsho, Koch, \& Halpin, 1987; Olsho et al., 1988; Schneider et al., 1980; Sinnott et al., 1983; Trehub et al., 1980). Two KrohnHite 3343 filters in series were used to achieve a nominal filter slope of $96 \mathrm{~dB} /$ oct. $^{2}$ The masker level, $35 \mathrm{~dB}$ pressure spectrum level, was chosen so that when the unfiltered masker noise was presented simultaneously with the interrupted stimulus, no gaps were detected by a panel of adult pilot subjects. The same spectrum level of the masker was then maintained in all conditions. The stimulus, and, in masked conditions, the masker were turned on at the beginning of the session and, except for the gaps during signal trials, remained on throughout the session.

A Sony E222 earphone was used to deliver sounds to all listeners. The frequency response of this earphone was relatively flat (i.e., it produced the same intensity) to about $6,000 \mathrm{~Hz}$, with a gradual roll-off at higher frequencies. An equalizer was used to ensure that the spectrum of the noise delivered by the earphone was flat $( \pm 2 \mathrm{~dB})$ to about $10,000 \mathrm{~Hz}$. Calibrations were performed in a 6-cc coupler (meant to approximate the volume of the external ear) using a Hewlett Packard 3521A spectrum analyzer and routinely checked with a Bruel \& Kjaer 2215 sound level meter (see Olsho et al., 1988, for details). The diameter of the earphone is approximately $1 / 2$ inch; it was placed in a foam cushion and held at the entrance to the ear canal with micropore tape. By taping the earphone cord to the back of the infant's shirt to reduce tension on the cord, we were generally able to maintain a stable earphone position throughout a session.

Testing was conducted in a singlewalled, sound-attenuating booth (IAC). The infant sat on a parent's lap, facing a window into an adjacent control room and a video camera in the test booth. There was a table directly in front of the parent and infant. An assistant was seated to the infant's left, and a smoked Plexiglas box containing lights and a mechanical toy, the "visual reinforcer," was placed to the infant's right at infant eye level.

Procedure.-Infants were tested using the Observer-based Psychoacoustic Proce-

\footnotetext{
${ }^{1}$ Spectrum level is defined as the average intensity of sound in a $1-\mathrm{Hz}$ band.

2 The filter slope specifies the degree to which frequencies falling beyond the cutoff of the filter are attenuated. A filter slope of $96 \mathrm{~dB} /$ octave, for example, would mean that a frequency 1 octave below the filter cutoff would be attenuated by $96 \mathrm{~dB}$ relative to the cutoff frequency. The degree of attenuation provided by the filter may not actually be achieved since the noise level in the sound generation system can be higher than the level achieved by the filter; hence, the "nominal" filter slope is typically given.
} 
dure (Olsho, Koch, Halpin, \& Carter, 1987). In this procedure, an observer, blind to trial type, uses the infant's behavior on each trial to decide whether a signal or no-signal trial has occurred. In the current experiment, a signal trial was defined as a trial on which gaps were presented; a no-signal trial was a period of equal duration during which the stimulus was continuous.

The infant was seated on a parent's lap in the test booth, and the earphone was placed on the infant's right ear. An assistant was seated to the infant's left and manipulated toys to maintain the infant in a quiet, attentive state, facing forward. The parent and the assistant listened to masking sounds presented over circumaural headsets to prevent them from hearing the stimuli presented to the infant and inadvertently influencing the infant's responses. The parent heard music; the assistant monitored activity in the control room.

The observer watched the infant from the control room, either through the window or over a video monitor. The noise stimulus was presented continuously from the beginning of the session. The observer began a trial when the infant was quiet and attending at midline. Signal trials were presented to the infant with a probability of 0.65 . A flashing LED indicated to the observer that a trial was in progress, but the observer did not know whether a signal (gap) or no-signal (continuous noise) trial was being presented. The observer used the infant's behavior to decide whether a signal or no-signal trial had been presented, and received feedback after each trial.

Each test session consisted of two phases, training and testing. During training, the duration of the gaps on signal trials was fixed at $100 \mathrm{~ms}$. If the observer judged that a signal had occurred on a signal trial, the visual reinforcer was activated as soon as the observer recorded the judgment and continued for $4 \mathrm{sec}$ after the end of the trial. If the observer judged that no signal had occurred on a signal trial, the reinforcer was activated for $4 \mathrm{sec}$ at the end of the trial, and an error was scored. If the observer judged that no signal had occurred on a no-signal trial, a correct rejection was scored, and if the observer judged that a signal had occurred on a no-signal trial, an error (false alarm) was scored. In no case was the reinforcer activated during or after a no-signal trial. The purpose of this procedure was to encourage the infant to respond to the gaps in anticipation of the onset of the reinforcer. The observer could then use whatever response the infant made (e.g., head turning, eye widening, cessation of activity) as the basis of his or her judgment on each trial. The training phase continued until the observer had reached a criterion of four of the last five signal trials correct and four of the last five no-signal trials correct.

During the testing phase, the visual reinforcer was activated only when the observer judged that a signal had occurred when a signal trial had actually been presented. Gap duration was varied to estimate a threshold, following PEST rules (Taylor \& Creelman, 1967; Spetner \& Olsho, 1990, describe the threshold estimation procedure in detail). Briefly, these rules specify that if the observer is correct at a given gap duration, the gap should be made shorter, while if the observer is incorrect at a gap duration, the gap should be made longer. When the observer goes from being correct to being incorrect as the gap duration is changed (i.e., a reversal occurs), then the amount by which the gap duration changes (the step size) is halved. The effect is to generate a binary search for the threshold. In the current experiment, the observer was considered correct at a given gap duration if at least three of the last four signal trials at that duration were correct. The observer was considered incorrect if fewer than three of the last four signal trials at a given duration were correct. The observer was required to maintain a false alarm rate below 0.25 during testing. Testing was continued until 50 signal trials had been presented, or until the observer's false alarm rate exceeded 0.25 , or until the infant's state precluded further testing. A typical test run lasted $20 \mathrm{~min}$. An example of an infant test protocol is shown in Figure 1 .

Thresholds were estimated as the gap duration at which the observer said "signal" $70 \%$ of the time. This duration was estimated by taking the proportion of "signal" judgments at each gap duration presented to an individual infant in a given condition and fitting a psychometric function to those data points using probit analysis (Finney, 1970). The fit of the function was assessed using a maximum likelihood criterion (Hall, 1968, 1981). The threshold for a session was used only if at least 30 signal trials were obtained, the false alarm rate did not exceed 0.25 , and the slope of the best-fitting function was greater than zero. If a session was excluded, thresholds were obtained in subsequent vis- 


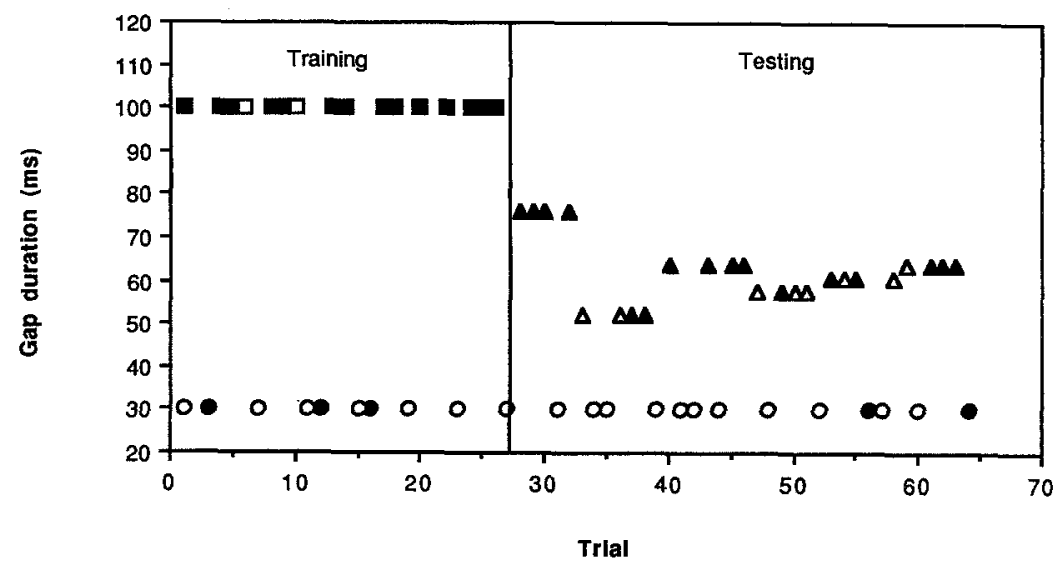

Frg. 1.-Example of a trial-by-trial protocol for a 12-month-old tested in the 8,000-Hz masker cutoff condition. Filled symbols represent trials on which the observer responded "signal"; circles are no-signal trials; squares are training signal trials; triangles are testing signal trials.

its if possible. If a condition was repeated, the entire training and testing procedure was completed on the return visit.

Adult thresholds were obtained using the same general procedure, except that the adults listened alone in the test booth and were asked to raise their hands when they heard gaps in the noise. An observer in the control booth recorded responses, and the reinforcer was activated as feedback to the adult following the same contingencies used in infant testing.

An attempt was made to test each subject under four conditions: no masker, highpass masker with $500-\mathrm{Hz}$ cutoff, high-pass masker with $2,000-\mathrm{Hz}$ cutoff, and high-pass masker with $8,000-\mathrm{Hz}$ cutoff. Thresholds in these four conditions were obtained in random order. All adults were able to complete the four thresholds within two 1-hour sessions. Infants were rescheduled as many times as possible to obtain four thresholds. However, only a few infants actually provided data in all four conditions; at least six infants at each age provided thresholds in each condition. The number of thresholds obtained in each condition are listed in Table 1 .

\section{Results}

The average gap detection threshold in each masking condition for listeners of various ages is shown in Figure 2. When adults were forced to use frequencies below 500 $\mathrm{Hz}$ to detect gaps, their gap detection thresholds averaged about $16 \mathrm{~ms}$. Adult thresholds improved to about $5 \mathrm{~ms}$ when frequencies as high as $8,000 \mathrm{~Hz}$ were available. These average thresholds are consistent with those typically reported for adults (e.g., Fitzgibbons \& Wightman, 1982; Irwin et al., 1981), and the improvement in performance with frequency has also been well documented in adults (e.g., Buus \& Florentine, 1982; Fitzgibbons, 1983; Shailer \& Moore, 1985).

Several aspects of infant performance are noteworthy. First, it is apparent that, in general, the infants do not perform as well as the adults do. Although that fact in itself is not startling, the size of the age effect is rather dramatic: 3- and 6-month-olds have average thresholds 40 to $60 \mathrm{~ms}$ higher than those of adults in all masking conditions. Compared to infants' fairly good pure tone thresholds and frequency difference thresholds (Olsho et al., 1988; Olsho, 1984), this is a large age difference. For example, in frequency discrimination, infant thresholds are roughly twice those of adults (e.g., Olsho, 1984; Sinnott \& Aslin, 1985), while in gap detection, infant thresholds are at least four times those of adults. Second, the effect of frequency on the gap detection threshold is similar for 3-month-olds, 6-month-olds, and adults: the threshold improves as higher frequencies are made available until the $8,000-$ $\mathrm{Hz}$ masker cutoff does not differ from the unmasked condition.

Third, the performance of the 12month-olds appears to differ from that of both younger and older listeners. The 12month-olds do no better than the 3- or 6month-olds with $2,000-$ or $8,000-\mathrm{Hz}$ masker cutoffs or in the unmasked condition. When the cutoff of the masker is as low as $500 \mathrm{~Hz}$, the 12-month-olds' average gap detection 
TABLE 1

Means and Standand Deviations of Other Measures of Gap Detection Performance

\begin{tabular}{|c|c|c|c|c|c|}
\hline Age & $\begin{array}{l}\text { Masker } \\
\text { Condition }\end{array}$ & $N$ & $\begin{array}{c}\text { False } \\
\text { Alarm Rate }\end{array}$ & $\begin{array}{l}\text { Trials to } \\
\text { Training } \\
\text { Criterion }\end{array}$ & $\begin{array}{l}\text { Psychometric } \\
\text { Function } \\
\text { Slope (z/ms) }\end{array}$ \\
\hline 3 & unmasked & 9 & $\begin{array}{l}.19 \\
(.05)\end{array}$ & $\begin{array}{l}22.11 \\
(12.15)\end{array}$ & $\begin{array}{l}5.83 \\
(.21)\end{array}$ \\
\hline 6 & unmasked & 12 & $\begin{array}{l}.19 \\
(.06)\end{array}$ & $\begin{array}{l}17.25 \\
(8.91)\end{array}$ & $\begin{array}{l}3.31 \\
(.35)\end{array}$ \\
\hline 12 & unmasked & $6 \ldots \ldots \ldots \ldots \ldots \ldots \ldots$ & $\begin{array}{l}.22 \\
(.04)\end{array}$ & $\begin{array}{l}24.17 \\
(9.58)\end{array}$ & $\begin{array}{l}4.48 \\
(.25)\end{array}$ \\
\hline adult & unmasked & 10 & $\begin{array}{l}.00 \\
(.00)\end{array}$ & $\begin{array}{c}8.00 \\
(1.33)\end{array}$ & $\begin{array}{l}1.87 \\
(.33)\end{array}$ \\
\hline 3 & $500 \mathrm{~Hz}$ & 6 & $\begin{array}{l}.20 \\
(.09)\end{array}$ & $\begin{array}{l}29.00 \\
(17.81)\end{array}$ & $\begin{array}{l}3.43 \\
(.50)\end{array}$ \\
\hline 6 & $500 \mathrm{~Hz}$ & 6 & $\begin{array}{l}.21 \\
(.03)\end{array}$ & $\begin{array}{l}23.00 \\
(15.40)\end{array}$ & $\begin{array}{l}5.83 \\
(.05)\end{array}$ \\
\hline 12 & $500 \mathrm{~Hz}$ & 6 & $\begin{array}{l}.22 \\
(.03)\end{array}$ & $\begin{array}{l}25.33 \\
(12.86)\end{array}$ & $\begin{array}{l}1.69 \\
(.49)\end{array}$ \\
\hline adult & $500 \mathrm{~Hz}$ & 10 & $\begin{array}{l}.05 \\
(.06)\end{array}$ & $\begin{array}{l}10.30 \\
(1.49)\end{array}$ & $\begin{array}{r}.97 \\
(.51)\end{array}$ \\
\hline 3 & $2,000 \mathrm{~Hz}$ & 6 & $\begin{array}{l}.22 \\
(.06)\end{array}$ & $\begin{array}{l}17.67 \\
(10.78)\end{array}$ & $\begin{array}{l}3.38 \\
(.16)\end{array}$ \\
\hline 6 & $2,000 \mathrm{~Hz}$ & 7 & $\begin{array}{l}.22 \\
(.02)\end{array}$ & $\begin{array}{l}23.86 \\
(10.82)\end{array}$ & $\begin{array}{l}4.24 \\
(.50)\end{array}$ \\
\hline 12 & $2,000 \mathrm{~Hz}$ & 6 & $\begin{array}{l}.21 \\
(.04)\end{array}$ & $\begin{array}{l}25.83 \\
(9.99)\end{array}$ & $\begin{array}{l}4.26 \\
(.41)\end{array}$ \\
\hline adult & $2,000 \mathrm{~Hz}$ & 11 & $\begin{array}{l}.03 \\
(.04)\end{array}$ & $\begin{array}{l}9.09 \\
(1.64)\end{array}$ & $\begin{array}{l}2.06 \\
(.35)\end{array}$ \\
\hline 3 & $8,000 \mathrm{~Hz}$ & 6 & $\begin{array}{l}.18 \\
(.06)\end{array}$ & $\begin{array}{c}25.17 \\
(18.60)\end{array}$ & $\begin{array}{l}8.31 \\
(.14)\end{array}$ \\
\hline 6 & $8,000 \mathrm{~Hz}$ & 9 & $\begin{array}{l}.23 \\
(.05)\end{array}$ & $\begin{array}{l}18.22 \\
(11.08)\end{array}$ & $\begin{array}{l}4.05 \\
(.27)\end{array}$ \\
\hline 12 & $8,000 \mathrm{~Hz}$ & 7 & $\begin{array}{l}.23 \\
(.02)\end{array}$ & $\begin{array}{l}22.43 \\
(10.05)\end{array}$ & $\begin{array}{l}4.79 \\
(.20)\end{array}$ \\
\hline adult & $8,000 \mathrm{~Hz}$ & 11 & $\begin{array}{l}.04 \\
(.07)\end{array}$ & $\begin{array}{c}9.10 \\
(1.64)\end{array}$ & $\begin{array}{l}1.79 \\
(.32)\end{array}$ \\
\hline
\end{tabular}

NoTE.-Standard deviations are in parentheses.

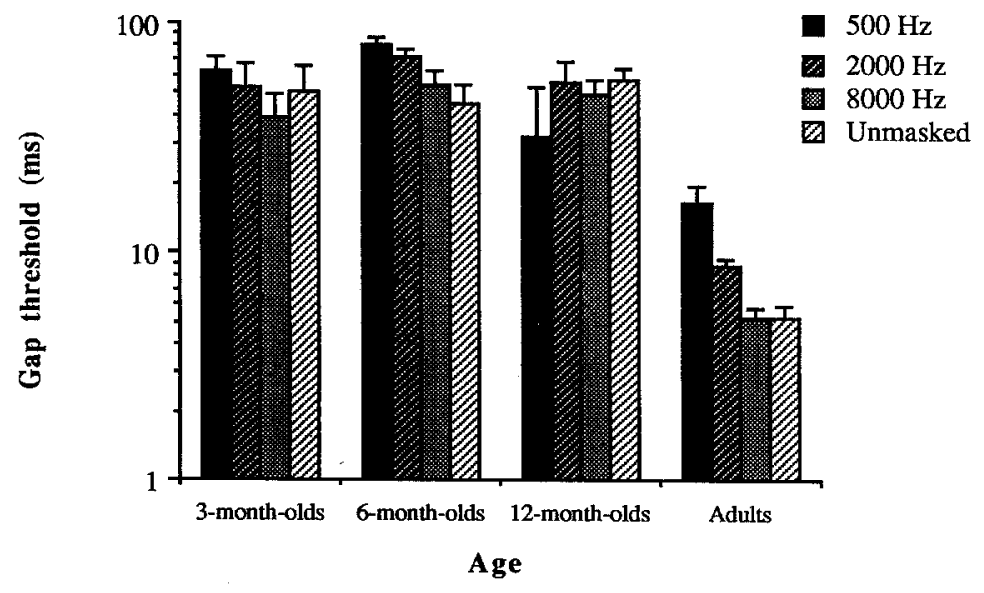

FIG. 2.-Average gap detection threshold ( $\pm 1 \mathrm{SE}$ ) as a function of masker condition for four age groups. Note that a logarithmic scale is used on both axes. 
Individual Gap Detection Thresholds of 12-Month-Olds and Adults in the 500-Hz MASKER CUTOFF CONDITION

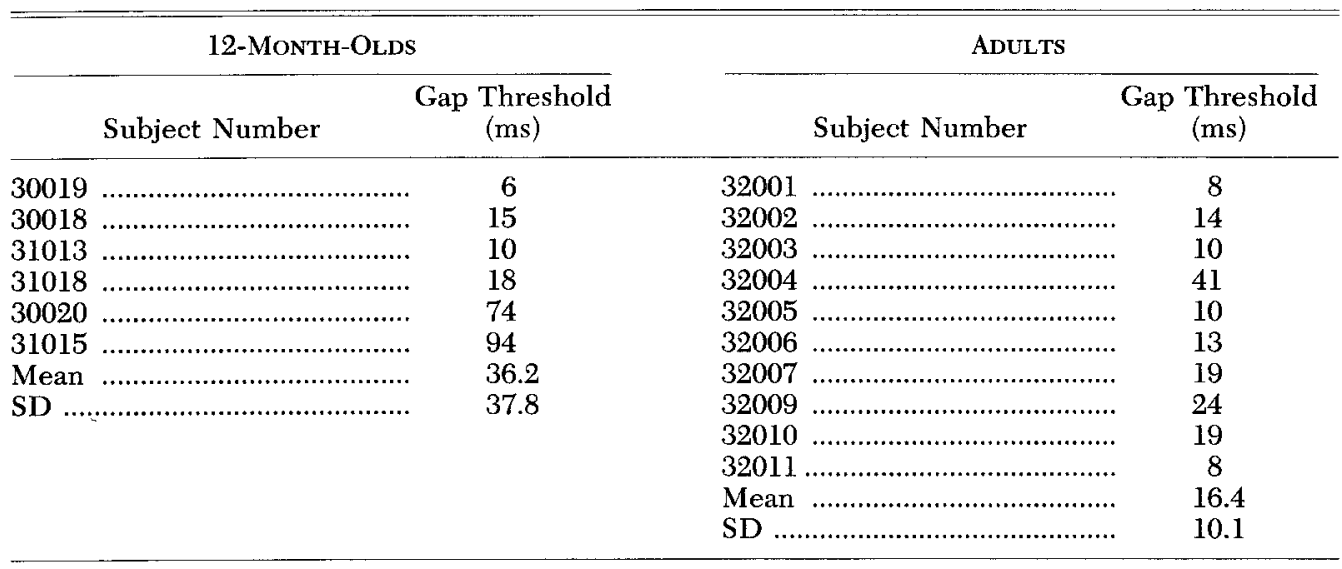

threshold approaches that of the adults, but the variability in performance is extremely high. Examination of the individual thresholds in this condition (Table 2) suggests a bimodal distribution of thresholds. Two of the six subjects performed as poorly as the younger infants, while the other four performed as well as adults. There was no evidence of a bimodal distribution of thresholds in any of the other ages or conditions. This finding is discussed further below and led us to test a second group of 12-month-olds in this condition (Experiment 2).

Gap thresholds were transformed using the logarithmic function to make the variances more homogeneous before applying analysis of variance (Winer, 1971). Because of the extreme variability among 12-montholds at $500 \mathrm{~Hz}$, this group was excluded from the analysis. An age (3) $\times$ masking condition (4) analysis of variance ${ }^{3}$ of the transformed thresholds showed a significant effect of age $[F(2,86)=108.9, p<.001]$, a significant effect of masking condition $[F(3,86)=8.4, p$ $<.001]$, but no effect of the age $\times$ masking condition interaction $[F(6,86)=.5, p=.8]$. One-way analysis of variance was used to examine the effect of age on the gap detection threshold in each masking condition. Twelve-month-olds were included in these analyses at 2,000 and $8,000 \mathrm{~Hz}$ and in the unmasked condition. The effect of age was significant at $500 \mathrm{~Hz}[F(2,194)=25.877$, $p<.001]$, at $2,000 \mathrm{~Hz}[F(3,26)=27.867$, $p<.001]$, at $8,000 \mathrm{~Hz}[F(3,29)=48.426, p$ $<.001]$, and in the unmasked condition $[F(3,33)=16.583, p<.001]$; in each of these conditions Tukey HSD multiple comparisons indicated that 3-, 6-, and 12-month-olds (where included) did not differ from each other, but that each infant group had significantly higher thresholds than the adults. Thus, the statistical analyses confirmed the trends that appear evident in Figure 2.

In order to better understand the nature of the age differences in gap detection thresholds, three additional performance measures were examined: false alarm rate, number of training trials to criterion, and slope of the psychometric function used to calculate the threshold. The means and standard deviations of these measures for each age group are listed in Table 1. Differences among the age groups were tested using one-way analysis of variance in each masking condition.

All infant groups had higher false alarm rates than adults in all conditions. Thus, one factor contributing to the age difference in thresholds could be age differences in response bias. However, unless response bias varied in a systematic way with masker condition, it could not explain why the nature of the age difference in threshold varied with masker condition. False alarm rate was transformed using an arcsin transformation

${ }^{3}$ The use of a factorial analysis was justified by the fact that none of the correlations between thresholds obtained from the same subjects in different masking conditions was significant after partialing out the effect of age. 
(Winer, 1971) for the statistical analysis. The effect of age was significant in each condition, unmasked $[F(3,33)=18.456, p<.001]$, $500 \mathrm{~Hz}[F(3,24)=7.918, p<.002], 2,000$ $\mathrm{Hz}[F(3,26)=34.457, p<.001]$, and 8,000 $\mathrm{Hz}[F(3,29)=23.956, p<.001]$. In each case, though, post hoc analyses showed the same pattern of age differences, 3-, 6-, and 12-month-olds all having significantly higher false alarm rates than adults. Thus, differences in response bias cannot account for the difference between $500 \mathrm{~Hz}$ and the other masking conditions.

The number of training trials to criterion may reflect the difficulty experienced by listeners in learning the detection task under different masking conditions, and one might predict that thresholds would be higher for listeners and conditions under which the task is more difficult to learn. Again, infants generally required more trials than adults to reach training criterion, as indicated in Table 1 . The one-way analysis of variance showed a significant effect of age in all conditions, unmasked $[F(3,33)=5.891, p<$ $.002], 500 \mathrm{~Hz}[F(3,24)=3.94, p<.028]$, $2,000 \mathrm{~Hz}[F(3,26)=7.074, p<.001]$, and $8,000 \mathrm{~Hz}[F(3,29)=3.357, p<.032]$. Newman Keuls analyses indicated that at 500 and $2,000 \mathrm{~Hz}$ and in the unmasked condition the infants all required significantly more trials to reach training criterion than the adults. At $8,000 \mathrm{~Hz}$, only the 3-month-olds required more training trials than the adults. This suggests that the $8,000-\mathrm{Hz}$ condition was relatively easier for the 6- and 12-month-olds to learn, but it is noteworthy that the three groups of infants had comparable thresholds in this condition nonetheless.

Finally, psychometric function slopes may affect threshold estimates in that thresholds estimated on shallower psychometric functions will be more variable than those estimated on steep psychometric functions (e.g., McKee, Klein, \& Teller, 1985). The slopes derived from probit analysis (Finney, 1970) were transformed using a $\tan ^{-1}$ transformation following Watson, Franks, and Hood (1972). Although examination of the average slopes listed in Table 1 suggests that the adults tended to have shallower psychometric functions than infants, one-way analysis of variance of the transformed slopes in each masking condition indicated no significant differences among the age groups in any masking condition. Thus, differences in gap detection thresholds do not appear to stem from differences in the accuracy of estimate for different age groups.

\section{Discussion}

It was clear from the above results that infants generally have poorer gap detection thresholds than adults under all masking conditions, although the effect of masking condition is similar for younger infants and adults. If one considers just the 3- and 6month-olds, the difference between the infants and adults is difficult to interpret. The fact that restricting the frequency region in which gaps are heard has a similar effect on the performance of these infants and adults supports the interpretation that temporal coding operates in a similar way in the two groups. The dramatic difference between infant and adult gap thresholds according to this interpretation would result from other factors influencing performance, such as attention or motivation.

One result that argues against attention as an important factor is that infant and adult psychometric function slopes in gap detection did not differ. Inattentiveness would be expected to make the psychometric function slope shallower (Schneider, Trehub, Morrongiello, \& Thorpe, 1989). This is a somewhat surprising result, because infant psychometric function slopes are typically shallower than those of adults, even when infant performance is fairly good (e.g., Olsho et al., 1987).

An alternate interpretation is that the age difference in thresholds results, at least partially, from immaturity of temporal coding. The finding that some 12-month-olds have adultlike gap detection thresholds at $500 \mathrm{~Hz}$ might be taken as support for this interpretation. If 12 -month-olds are in a period of rapid development of temporal coding, then high variability in performance would not be unexpected. Given the small number of 12-month-olds who completed testing at $500 \mathrm{~Hz}$, however, little faith can be put in the result. In Experiment 2 an additional group of 12 -month-olds was tested with a $500-\mathrm{Hz}$ masker cutoff to determine whether the result was replicable.

\section{Experiment 2}

\section{Method}

Subjects.-The subjects were 11 12month-old infants and five 20-30-year-old adults meeting the inclusion criteria described for Experiment 1. These subjects also passed tympanometry, a screening test for middle ear dysfunction, on the test date. An additional eight infants did not provide a threshold: four did not reach training crite- 


\section{Child Development}

rion, and four did not complete enough test trials.

Stimuli and apparatus.-The stimuli were the same as those used in the $500-\mathrm{Hz}$ masker cutoff condition in Experiment 1. A General Radio 1381 noise generator produced the stimulus (gapped) noise. A Grason-Stadler 901B noise generator produced the masking noise. The masking noise was high-pass filtered using a Kemo VBF $25 \mathrm{MD}$ filter with a nominal slope of $90 \mathrm{~dB} /$ octave. Except for the earphone, the rest of the apparatus was the same as in Experiment 1.

An Etymotic insert earphone (ER-1) was used to deliver sounds to the listeners. This earphone has a flat frequency response over a broad frequency range, eliminating the need for equalization. The foam ear tips that held the delivery tube in place were trimmed to fit the infants' ear canals. Infants generally tolerate the insert earphones as well as or better than other earphones, and they deliver the stimulus at a more consistent intensity. Calibrations were performed in a Zwislocki coupler, ${ }^{4}$ but in other respects as in Experiment 1.

Procedure.-Each listener was tested in a single condition, the $500-\mathrm{Hz}$ masker condition of Experiment 1. The test method, the Observer-based Psychoacoustic Procedure, was the same as in Experiment 1. General aspects of the procedure were the same, but several changes were made in the psychophysical procedure in an attempt to reduce the variability in infant performance.

Each session included two training phases. In the first training phase, signal trials were presented with a probability of 0.8 and the reinforcer was activated on signal trials, whether or not the observer responded correctly. Gap duration was $125 \mathrm{~ms}$. This phase ended when the observer was correct on at least four of the last five consecutive trials as long as at least one of the correct trials was a no-signal trial. In the second training phase, the probability of a signal was 0.50 , and the reinforcer was activated only when the observer correctly identified a signal trial. Gap duration was $125 \mathrm{~ms}$. This phase continued until the observer was cor- rect on at least four of the last five signal trials and on at least four of the last five nosignal trials.

During the test phase, threshold was estimated using a one-up, two-down adaptive method (Levitt, 1971). The probability of a signal trial was 0.50 . Gap duration began at $125 \mathrm{~ms}$. If the observer was correct on two consecutive trials (signal or no-signal), gap duration was reduced. If the observer was incorrect on one trial, gap duration was increased. The size of the step in gap duration was varied using PEST rules as in Experiment 1 . The test phase continued until at least eight reversals had occurred. Threshold was defined as the average of the gap durations at which reversals occurred, excluding the first two reversals.

The advantage of this method over that used in Experiment 1 is that because responses on both signal and no-signal trials affect the threshold, the observer cannot obtain low thresholds simply by responding "signal" more often. Computer simulations indicate that this version of the one-up, twodown rule converges on approximately the $70 \%$ correct point on the psychometric function, and this test method and the method used in Experiment 1 produce the same average threshold for infants (Werner \& Marean, 1991).

\section{Results}

The average gap threshold of 12 month-olds in Experiment 2 was $62.2 \mathrm{~ms}$ $(\mathrm{SEM}=9.0)$, while the average for the adults was $13.2 \mathrm{~ms}(\mathrm{SEM}=2.3)$. The 12 month-olds' average was much poorer than in Experiment 1; in fact, this mean would fall with those of 3- and 6-month-olds for Experiment 1 . Thus, one might conclude that there is little evidence of improvement in gap detection between 3 and 12 months in any condition. The only hint that there is any difference here was the distribution of thresholds in the two age groups, shown in Figure 3. Although there is no overlap between the infants and adults in gap thresholds, the distribution of infant thresholds still appears to be bimodal. Six of the 11 infants had thresholds between 30 and $49 \mathrm{~ms}$, and four had thresholds higher than $90 \mathrm{~ms}$.

\footnotetext{
${ }^{4}$ An insert earphone fits into the listener's ear canal. The advantage of an insert is that there is little variability in the intensity of stimulus because the position of the delivery tube is less variable. Because the volume of the ear canal beyond the end of the delivery tube is smaller than the volume of the ear canal beyond an earphone that sits outside the ear canal, calibrations are performed in a smaller coupler. The Zwislocki coupler gives a more accurate calibration value than a 2 -cc coupler at high frequencies.
} 
Werner et al.

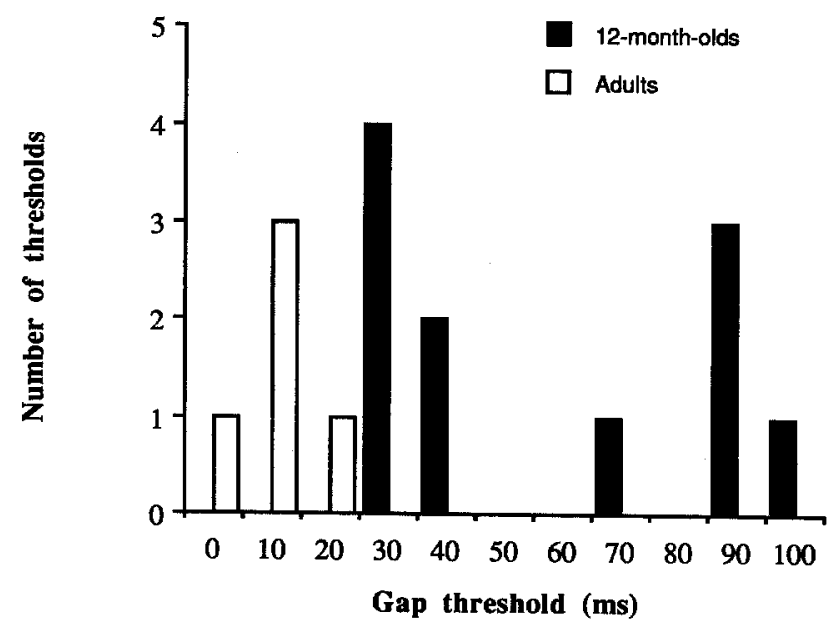
iment 2

FIG. 3.-Frequency distribution of gap detection thresholds for 12-month-olds and adults in Exper-

Thus, although the best 12-month-olds in this sample were not as good at gap detection as adults, they are better than the 3 - and 6-month-olds tested at $500 \mathrm{~Hz}$ in Experiment 1 . It should be noted, moreover, that it was rare to find infants in any other condition in Experiment 1 whose thresholds fell within $10 \mathrm{~ms}$ of the worst adult in the same condition. This occurred four times in 80 thresholds, twice in the unmasked condition (a 3-month-old and a 6-month-old), once in the $500-\mathrm{Hz}$ condition (a 3-month-old), and once in the $2,000-\mathrm{Hz}$ condition (a 12-monthold). Finally, 12-month-olds' gap detection thresholds may have been somewhat poorer in Experiment 2 as a result of changes in procedure. Although the two procedures produce the same results in tone detection (Werner \& Marean, 1991), it is possible that this would not be the case in gap detection. At this point, the safest conclusion may be that 12-month-olds are not different from younger infants in gap detection. That we continue to find 12-month-olds who perform fairly well at $500 \mathrm{~Hz}$, however, suggests that improvement in the gap detection threshold may be occurring at this age.

\section{General Discussion}

The major findings of this study are threefold. First, infants generally perform quite poorly in gap detection. Second, the effects of restricting the range of frequencies available for detecting gaps are qualitatively similar for infants and adults. Third, there is a suggestion that improvement in gap detection performance is occurring around 12 months of age and that this improvement occurs first in the case where only low frequency information is available for gap detection.

These results are consistent with Morrongiello and Trehub's (1987) finding that 6 -month-olds required a greater change in the duration of repeated noise bursts to detect a change, and with Wightman et al.'s (1989) report that 3-year-olds had higher gap detection thresholds than adults. The 12month-olds who performed well in gap detection at low frequencies here performed, on average, a little worse than Wightman et al.'s (1989) 3-year-olds did in their $400-\mathrm{Hz}$ condition. Infants in all the other conditions in this study performed much worse than Wightman et al.'s (1989) 3-year-olds. The psychophysical data thus suggest substantial improvement in auditory temporal resolution over the early years of life.

Numerous studies have demonstrated that infants as young as 1 month of age can discriminate between speech sounds that vary along a temporal dimension (reviewed by Aslin, Pisoni, \& Jusczyk, 1983). Is the finding that infants have such poor gap detection thresholds inconsistent with that literature? In fact, it appears that when temporal information alone is provided, 6-8month-olds may have difficulty discriminating speech stimuli (Eilers, Morse, Gavin, \& Oller, 1981). Aslin et al. (1983) suggest that infants may have been using nontemporal cues to discriminate between sounds in earlier experiments. Thus, it appears that the poor gap detection performance reported 
here is not inconsistent with the infant speech perception literature.

There are at least three classes of factors that could contribute to age-related improvement in gap detection performance. The first is maturation of temporal coding in the primary auditory pathways. Brugge and his colleagues (Brugge, Javel, \& Kitzes, 1978; Kettner, Feng, \& Brugge, 1985) have shown that phase locking, the tendency of neurons to respond in a manner that is time-locked to a stimulus waveform, gradually improves following the onset of auditory function in kittens. Unlike absolute sensitivity and frequency resolution, which mature very quickly once the peripheral auditory system begins to function, temporal coding matures over a longer time course and appears to mature later at more central loci (Brugge et al., 1978; Kettner et al., 1985; Sanes \& Rubel, 1988). Given the protracted time course of development in temporal coding and that the rate of development is slower in humans than in other mammals, it is possible that one would see continuing maturation of temporal coding during human infancy. In fact, the latency of the auditory brainstem response (ABR) continues to mature until some time after 12 months of age in humans, and this age-related change is usually attributed to increases in the synchrony of evoked neural activity (e.g., Eggermont, 1985). Since neural synchrony is a by-product of phase locking, one might conclude that maturation of temporal coding in humans continues at least until 12 months postnatal age. Finally, Brugge and his colleagues (Brugge et al., 1978; Kettner et al., 1985) have shown that the first neurons to achieve adultlike phase locking are those reponding to low frequencies. The only infants we observed who approached adult performance in gap detection were 12-month-olds listening at $500 \mathrm{~Hz}$. At the same time, the age differences in gap detection observed here are larger than would be predicted from the data on neural development, and it is not clear that one would predict a maturational course that exceeds 3 years in duration. It is also not obvious that one would expect to see an adultlike frequency effect in gap detection in infants if the infant system were substantially immature, since the variability in neural response resulting from immaturity would be likely to swamp the differences in variability associated with frequency.

Another factor that may contribute to the infant-adult performance difference in gap detection is the effective level of the stimu- lus. The stimuli here should have been well above threshold for all subjects at a spectrum level of $30 \mathrm{~dB}$ SPL, but since infants require higher intensities of sound for simple detection (e.g., Olsho et al., 1988; Trehub et al., 1980), and since the stimuli here were presented at a fixed intensity, the sensation level of the stimuli would be lower for the infants. Sensation level is known to affect gap detection threshold (e.g., Fitzgibbons, 1983), and it is likely that some of the difference between the younger infants and adults can be accounted for by sensation level differences. It is unlikely that sensation level can completely account for the observed age differences in gap detection performance for several reasons. First, infant-adult differences in sensation level on the order of those typically reported (e.g., Olsho et al., 1988) are far too small to account for the large age difference in gap detection performance (e.g., Fitzgibbons, 1983). Second, age differences in absolute sensitivity are frequency dependent (e.g., Olsho et al., 1988; Trehub et al., 1980), but for 3-and 6-month-olds, age differences in gap detection are constant across frequencies. To the extent that sensation level differences do contribute, however, it should be possible to show that infants improve more rapidly than adults do as the level of the stimulus is increased beyond the level used here.

Clearly, nonsensory mechanisms that affect infant responses must be considered. At all ages, infants tend to require more trials to learn the task and to have a more liberal response bias during testing than adults do. This suggests a general inefficiency in infant processing of auditory information. More specifically, Werner and Bargones (1991) showed that 6-month-olds had difficulty detecting a sound in the presence of an irrelevant sound, even when the irrelevant sound was at a distant frequency, while adult performance was unaffected by the irrelevant sound. In other words, adults listened selectively for the target, while infants did not. The fact that adults in the present study achieved gap detection thresholds close to those reported in studies using narrow-band stimuli implies that they listened selectively for gaps in the optimal frequency region. If infants did not listen selectively, their performance would be relatively poor, since on many trials they would be listening in a nonoptimal frequency region. A frequency effect would still be predicted since the infants would happen to be listening in an optimal frequency region on some trials. 


\section{Werner et al. 271}

This idea leads to the prediction that infants might do better in detecting gaps in a narrow band stimulus.

If anything, the finding that some 12 month-olds do relatively well in gap detection at $500 \mathrm{~Hz}$ suggests that temporal resolution is relatively mature. Why this only occurs in the $500-\mathrm{Hz}$ condition is not clear, but it may involve some interaction between the factors described above. For example, 12-month-olds may have mature temporal resolution but only be able to listen selectively when gaps occur in a restricted frequency region. This hypothesis could be tested by examining infant gap detection when bandwidth and frequency are manipulated independently.

It is likely that some combination of factors-temporal coding, sensation level, general processing efficiency, or selective listening-is responsible for the large differences between infants and adults in gap detection performance. Moreover, it need not be the case that a single factor or even a single combination of factors accounts for improvement over the entire developmental course of gap detection. Studies that use similar stimuli and methods to assess performance over a broader age range, testing specific hypotheses about the nature of the agerelated change in temporal processing, are clearly in order.

\section{References}

Aslin, R. N., Pisoni, D. B., \& Jusczyk, P. W. (1983). Auditory development and speech perception in infancy. In M. M. Haith \& J. J. Campos (Eds.), P. H. Mussen (Series Ed.), Handbook of child psychology: Vol. 2. Infancy and developmental psychobiology (4th ed., pp. 573-688). New York: Wiley.

Brugge, J. F., Javel, E., \& Kitzes, L. M. (1978). Signs of functional maturation of peripheral auditory system in discharge patterns in anteroventral cochlear nucleus of kittens. Journal of Neurophysiology, 41, 1557-1579.

Buus, S., \& Florentine, M. (1982). Detection of temporal gap as a function of level and frequency. Journal of the Acoustical Society of America, 72, S89.

Davis, S. M., \& McCroskey, R. L. (1980). Auditory fusion in children. Child Development, 51, 75-80.

Dreschler, W. A., \& Plomp, R. (1980). Relation between psychophysical data and speech perception for hearing-impaired listeners. Journal of the Acoustical Society of America, 68, 1608-1615.
Eggermont, J. (1985). Physiology of the developing auditory system. In S. E. Trehub \& B. A. Schneider (Eds.), Auditory development in infancy (pp. 21-46). New York: Plenum.

Eilers, R. E., Morse, P. A., Gavin, W. J., \& Oller, D. K. (1981). Discrimination of voice onset time in infancy. Journal of the Acoustical Society of America, 70, 955-965.

Finney, D. J. (1970). Probit analysis. Cambridge: Cambridge University Press.

Fitzgibbons, P. J. (1983). Temporal gap detection in noise as a function of frequency, bandwidth, and level. Journal of the Acoustical Society of America, 74, 67-72.

Fitzgibbons, P. J., \& Wightman, F. L. (1982). Gap detection in normal and hearing-impaired listeners. Journal of the Acoustical Society of America, 72, 761-765.

Gottlieb, G. (1985). On discovering significant acoustic dimensions of auditory stimulation for infants. In G. Gottlieb \& N. A. Krasnegor (Eds.), Measurement of audition and vision in the first year of life: A methodological overview (pp. 3-30). Norwood, NJ: Ablex.

Hall, J. L. (1968). Maximum Iikelihood sequential procedure for estimation of psychometric functions. Journal of the Acoustical Society of America, 44, 370.

Hall, J. L. (1981). Hybrid adaptive procedure for estimation of psychometric functions. Journal of the Acoustical Society of America, 69, 1763-1769.

Irwin, R. J., Ball, A. K. R., Kay, N., Stillman, J. A., \& Rosser, J. (1985). The development of auditory temporal acuity in children. Child Development, 56, 614-620.

Irwin, R. J., Hinchcliffe, L. K., \& Kemp, S. (1981). Temporal acuity in normal and hearingimpaired listeners. Audiology, 20, 234-243.

Kettner, R. E., Feng, J-Z., \& Brugge, J. F. (1985). Postnatal development of the phase-locked response to low frequency tones of auditory nerve fibers in the cat. Journal of Neuroscience, 5, 275-283.

Levitt, H. (1971). Transformed up-down methods in psychoacoustics. Journal of the Acoustical Society of America, 49, 467-477.

McKee, S. P., Klein, S. A., \& Teller, D. Y. (1985). Statistical properties of forced-choice psychometric functions: Implications of probit analysis. Perception \& Psychophysics, 37, 286-298.

Morrongiello, B. A., \& Trehub, S. E. (1987). Agerelated changes in auditory temporal perception. Journal of Experimental Child Psychology, 44, 413-426.

Olsho, L. W. (1984). Infant frequency discrimination. Infant Behavior and Development, 7, 27-35.

Olsho, L. W., Koch, E. G., Carter, E. A., Halpin, C. F., \& Spetner, N. B. (1988). Pure-tone sen- 


\section{Child Development}

sitivity of human infants. Journal of the Acoustical Society of America, 84, 13161324.

Olsho, L. W., Koch, E. G., \& Halpin, C. F. (1987). Level and age effects in infant frequency discrimination. Journal of the Acoustical Society of America, 82, 454-464.

Olsho, L. W., Koch, E. G., Halpin, C. F., \& Carter, E. A. (1987). An observer-based psychoacoustic procedure for use with young infants. Developmental Psychology, 23, 627-640.

Pisoni, D. B. (1977). Identification and discrimination of the relative onset of two component tones: Implications for voicing perception in stops. Journal of the Acoustical Society of America, 61, 1452-1461.

Sanes, D. H., \& Rubel, E. W. (1988). The development of stimulus coding in the auditory system. In A. F. Jahn \& J. Santos-Sacchi (Eds.), Physiology of the ear (pp. 431-456). New York: Raven.

Schneider, B. A., Trehub, S. E., \& Bull, D. (1980). High-frequency sensitivity in infants. Science, 207, 1003-1004.

Schneider, B. A., Trehub, S. E., Morrongiello, B. A., \& Thorpe, L. A. (1989). Developmental changes in masked thresholds. Journal of the Acoustical Society of America, 86, 17331742.

Shailer, M. J., \& Moore, B. C. J. (1983). Gap detection as a function of frequency, bandwidth, and level. Journal of the Acoustical Society of America, 74, 467-473.

Shailer, M. J., \& Moore, B. C. J. (1985). Detection of temporal gaps in bandlimited noise: Effects of variations in bandwidth and signalto-masker ratio. Journal of the Acoustical Society of America, 77, 635-639.
Sinnott, J. M., \& Aslin, R. N. (1985). Frequency and intensity discrimination in human infants and adults. Journal of the Acoustical Society of America, 78, 1986-1992.

Sinnott, J. M., Pisoni, D. B., \& Aslin, R. M. (1983). A comparison of pure tone auditory thresholds in human infants and adults. Infant $\mathrm{Be}$ havior and Development, 6, 3-17.

Spetner, N. B., \& Olsho, L. W. (1990). Auditory frequency resolution in human infancy. Child Development, 61, 632-652.

Taylor, M. M., \& Creelman, D. C. (1967). PEST: Efficient estimates on probability functions. Journal of the Acoustical Society of America, 41, 782-787.

Trehub, S. E., Schneider, B. A., \& Endman, M. (1980). Developmental changes in infants' sensitivity to octave-band noises. Journal of Experimental Child Psychology, 29, 283-293.

Watson, C. S., Franks, J. R., \& Hood, D. C. (1972). Detection of tones in the absence of external masking noise: $I$. Effects of signal intensity and signal frequency. Journal of the Acoustical Society of America, 52, 633-643.

Werner, L. A., \& Bargones, J. Y. (1991). Sources of auditory masking in infants: Distraction effects. Perception \& Psychophysics, 50, 405-412.

Werner, L. A., \& Marean, G. C. (1991). Methods for estimating infant thresholds. Journal of the Acoustical Society of America, 90, 1867-1875.

Wightman, F., Allen, P., Dolan, T., Kistler, D., \& Jamieson, D. (1989). Temporal resolution in preschool children. Child Development, 60, 611-624.

Winer, B. J. (1971). Statistical principles in experimental design. New York: McGraw-Hill. 
This document is a scanned copy of a printed document. No warranty is given about the accuracy of the copy. Users should refer to the original published version of the material. 